Organisational learning in forensic fingerprint investigation : Solving critical challenges with organisational rule construction.

\title{
Mustonen, Virpi
}

2017-06

Mustonen , V , Tuunainen , J , Pohjola , P \& Hakkarainen , K 2017 , ' Organisational learning in forensic fingerprint investigation : Solving critical challenges with organisational rule construction. ' , Learning, Culture and Social Interaction, vol. 13 , pp. 75-89 . https://doi.org/10.1016/j.Icsi.2017.03.0

http://hdl.handle.net/10138/222888

https://doi.org/10.1016/j.lcsi.2017.03.001

unspecified

submittedVersion

Downloaded from Helda, University of Helsinki institutional repository.

This is an electronic reprint of the original article.

This reprint may differ from the original in pagination and typographic detail.

Please cite the original version. 
Final draft of Mustonen, V., Tuunainen, J., Pohjola, P. \& Hakkarainen, K. (in press). Organizational learning in forensic fingerprint investigation: Solving critical challenges with organizational rule construction. Learning, Culture and Social Interaction.

\author{
Organisational learning in forensic fingerprint investigation: Solving critical \\ challenges with organisational rule construction.
}

Virpi Mustonen, National Bureau of Investigation, P.O. Box 285, FI-01301 Vantaa, Finland. virpi.mustonen@poliisi.fi, tel. +358 407016666.

Juha Tuunainen, University of Oulu, Oulu Business School, P.O. Box 4600, FI-90014 University of Oulu Finland. juha.tuunainen@ oulu.fi, tel. +358 504624058.

Pasi Pohjola, National Institute of Health and Welfare, P.O. Box 30, FI-00271 Helsinki, Finland. pasi.pohjola@thl.fi, tel.+358405507263.

Kai Hakkarainen, University of Helsinki, Faculty of Behavioural Sciences, Siltavuorenpenger 5 A, P.O. Box 9, FI-00014 University of Helsinki Finland. kai.hakkarainen@ @elsinki.fi, tel. +358 50 4129572.

\begin{abstract}
The present study analyses data collected from a series of developmental seminars in a fingerprint laboratory during which fingerprint examiners jointly discussed and developed their work processes, analytical methods, decision-making criteria and rules of documentation. The analysed organizational development took place in the context of moving from paper to digital documentation and from individually to collectively mastered work process. The fingerprint examiners who participated in the seminar series jointly reflected on their existing professional rules and operational practices, improvement of which was called for to facilitate organizational learning. The analysed data set consists of 10 audio-recorded developmental seminars with written documents as well as notes and decisions that were made during the seminar. The results of the study will reveal the complex ways in which the fingerprint examiners share their practical professional knowledge and collectively create decision-making criteria and rules of investigative practices so as to adapt their work practices to the changing quality requirements, evolving international standards and digitalization of research documentation.
\end{abstract}

Keywords learning, rules, fingerprint, expertise, digitalization 


\section{Introduction}

The purpose of the present study is to examine how challenges of digitalization of fingerprint investigation are addressed in the developmental seminars of fingerprint examiners in the Forensic Laboratory of the National Bureau of Investigation (NBI) in Finland. Traditionally, fingerprint examiners' work has relied on personal capabilities of analyzing and processing latents with actual physical evidence extracted from crime scenes in the form of paper, photos and tapes. The examiners' work process did not provide many possibilities for quality assessment, and the level of documentation during the investigative process remained minimal. Digitalisation, however, brought new technological means with the help of which the work could be further developed. In 2011, for instance, Laboratory Information Management System (LIMS) was adopted in NBI to mediate almost all of the laboratory's work processes and services, a change which made it possible to develop fingerprint investigation towards a novel, collective work process with higher quality requirements. The digitalized examination also made the divergence of personal practices visible and elicited documentation of all stages of the examination. Additionally, it forced the fingerprint community to go beyond the former, often vague, methodological criteria and further develop the rules of its practice.

In order to analyze the above-mentioned process, the present study will draw ideas from research on expert work and organizational learning as well as literature on rule-creation and following. With the help of data coming from a developmental seminar and related written documentation, it will reveal the complex ways in which the fingerprint examiners at the National Bureau of Investigation in Finland shared their everyday practical knowledge and collectively created their decision-making criteria and rules of investigative practices so as to adapt their work processes to the changing quality requirements, evolving international standards and digitalization of the research instrumentation.

\section{Challenges for transforming practices in fingerprint examination}

The forensic science community consists of practitioners and scientists with a broad range of disciplines with its own technologies and practices, as well as techniques and methodologies. The nature of fingerprint analysis is historically formed by practices and knowledge, shaped by the values, motivations, emotions and purposes of the examiners and the institutions in which they work (Edwards \& Daniels, 2012; Charlton, Frazer-Mackenzie \& Dror, 2010). It is a complex process in matching two fingerprints, an unidentified fingerprint (latent) found at the crime scene and one from the register. Because of lack of mandatory standardization (e.g., operational principles and procedures), the methods and practices of examination have been locally-developed. Although joint protocols are followed, standards are often not used in a meaningful way (NAS, 2009).

Nevertheless, fingerprint examiners are expected to state their conclusions according to standardized rules and produce accurate, well-justified, and adequately documented decisions. Examiners are also encouraged to adaptively develop their working methods, examination processes and documentation. Due to digitalization, fingerprint examiners have to cultivate new epistemic practices mediated by digitalized instruments and practices. Furthermore, examiners have to deal with tightening quality criteria and accountability requirements when they encounter fuzzy cases and conflicting interpretations (Mustonen et al. 2015).

In conjunction with digitalization of instruments, fingerprint examination is also becoming more international in nature; investigators collaborate with their international counterparts, and national efforts are mediated by various international standards and quality requirements. This is partially 
because the fingerprint domain has had challenging situations due to misidentifications, e.g., in the USA and UK (Saks \& Koehler, 2005; U.S Department of Justice, 2006). International guidelines, norms, standards and scientific studies have tried to push those in the forensic domain to develop their practices further, with little success. These norms regulate the fingerprint examination which is also subject to individual variation in judgments, decisions, working practices, and documentation. National examination systems are, moreover, being developed and refined according to accumulating international research and evidence revealing challenges and limitations related to transparency and criteria. Consequently, professional expert systems, including those in fingerprinting, are increasingly expected to incorporate scientific methods and practices. The fingerprint examination community may be seen as an example of a professional epistemic culture (Nerland \& Jensen 2012, see also Nerland 2012; Jensen, Lahn, \& Nerland, 2012), one that relies both on professional knowing and scientific knowledge. Digital transformations transform personal and collective knowledge processes to visible and durable aspects of everyday work, leading to new kinds of transparency and accountability requirements (Jensen, Lahn, \& Nerland, 2012; Nerland \& Jensen, 2012).

Learning to do fingerprint analysis requires sophisticated expertise acquired through years of training and practical experience (Ericsson 2006). Mustonen and Hakkarainen (2015) analysed the development of two apprentices' adaptive expertise in fingerprint examination across a two-year training program. Their study, alongside with that of Mustonen and others (2015), confirmed that professional expertise is, to a large extent, based on tacit or implicit knowing; experts know more than they can tell (Polanyi, 1966) and often cannot provide reliable verbal descriptions of their reasoning process. Examiners' internalized professional knowledge provides psychological tools (Vygotsky 1978) for separating significant cues and signs from non-significant background. Goodwin's (1994) theory of professional vision assists in understanding and explaining experts' sophisticated visual competencies in recognizing complex patterns when comparing target fingerprints (latents found at a crime scene) with filed prints. Such visual capabilities allow experts to make well-justified inferences based only on partial and limited information. Goodwin (1994) categorized professionals' visual activity according to three practices; coding, highlighting, and producing and articulating material representations. As illustrated by Mustonen and others (2015), coding by marking minutiae in latents enables making AFIS (Automated Fingerprint Identification System) database searches and comparisons with the candidate's fingerprints. By highlighting disturbances and colour coding ridge flows (i.e. special details) or minutiae, the examiner makes his or her perceptions visible and shareable with other experts. Constructing external material representations involves manipulating fingerprint images in various ways by using AFIS and/or image manipulation programs (e.g., Photoshop) and by also producing written annotations which ground and justify one's interpretations. Working with digital samples is likely to considerably affect examiners' professional vision in respect of providing ways of transforming, enlarging, enhancing, and modifying images in various ways.

The same mechanisms that allow an expert to detect patterns based only on fragmented and limited information, may, however, lead to mistakes and error. Human reasoning is affected by cognitive, confirmation bias (Houses of Parliament, 2015a; Houses of Parliament, 2015b; Dror, 2013; Kassin, Dror \& Kukucka, 2013; Dror \& Hampikian, 2011; Dror, Champod, Langenburg, Charlton, Hunt \& Rosenthal, 2011), i.e., a tendency to selectively attend to evidence that supports one's own expectations or hypotheses. Due to the tacit or implicit nature of expert knowing (Schank, 1999), the fingerprint examiner may not be aware of the impact of heuristics and biases on his or her reasoning and decision making. Earlier studies have indicated a wide variation of results and interpretations in fingerprint case work (Ulery et al. 2016; Ulery et al. 2014; Mustonen et al. 2015). Technical errors usually involve erroneous exclusions, missed identifications, and inappropriate 
inconclusive or 'no value' decisions (Dror, 2013; Black, 2012; Dror \& Charlton, 2006; Kruger \& Dunning, 1999). The quality of the latent and expectations regarding the case being investigated also affect examination in the challenging, ambiguous and "bias-danger-zone" of decision situations (Dror, 2016, 2015; Dror et al. 2005). Fingerprint identification is thus more vulnerable to internal and external task-irrelevant information and biases when the difficulty of the task increases (Black, 2012; Schiffer \& Champod, 2007; Mattijssen, et al. 2015). Consequently, there are frequent occasions in which fingerprint examiners disagree about the same latent. Using the new collectivized examination system mediated by LIMS, Mustonen and others (2015) investigated professional fingerprint examiners' independent discrepant decisions concerning challenging latents during fingerprint analysis and identification. The study revealed that the examiners used partial and limited information in making judgments about the difficult and distorted latents. They appeared also to be involved in active, constructive efforts to mentally repair poor latents by supplementing information where gaps existed.

The fingerprint community is also affected by different quality standards (e.g., ISO 17025), The Best Practice Manuals of ENFSI (European Network of Forensic Science Institutes), SWGFAST Guidelines, a variety of academic and non-academic studies and literature and an uncounted, massive amount of organisational and international formal and non-formal norms and guides which make the work challenging. The installation of a quality-management system, and the requirements of accreditation and certifications make this more challenging. Digitalization brings about pressures to change the old ways of working. New models, tools, processes and method need to be developed and understood.

\section{Organizational learning conceptualized as transformation of institutional rules}

Fingerprint examination communities have developed shared guidelines that direct and assist examiners in working with fingerprints of varying quality. Rules that fingerprint examiners follow are not always well-defined, and the examiners themselves may not always be reflectively aware of the rules they are following. They are working with complex and heterogeneous cases, and the quality of fingerprints encountered varies a great deal. Even in cases of having well-defined rules and norms of examination, contextual interpretations are needed to apply them to the informationrich latents worked on. Examiners become consciously aware of their rules when arriving at different conclusions or when asked in discussions to justify their decisions. Examiners are also likely to follow shared rules and arrive at similar conclusions straightforwardly when encountering high-quality fingerprints; different interpretations and difficulties in following rules emerge when they encounter poor or messy fingerprints. Dror and Rosenthal (2008), for instance, have demonstrated that there is a significant bias effect in analyzing fingerprints when contextual information of an individual fingerprint is manipulated. To manage such variance, organizational actors have taken initiatives to develop and introduce more stable and articulate systems of professional rules, standards and guidelines. There is a need for modern solutions to achieve more reliability in complex and challenging latents and avoid unnecessary risks in interpretations and perceptions in decision making. However, the error rate of identification is not high (Ulery et al. 2011). It is often critical, for instance, to anchor examination only on latents being examined rather than rely on contextual information regarding whether other fingerprints collected from the crime scene support the conclusion.

Previously, it has been acknowledged that fingerprint analysis is characterized by variance in the systems of analysis and decision-making both at the level of individual investigations and organizational practices. Moving to digitalized examination opened up by Laboratory Information Management System (LIMS) and Automated Fingerprint Identification System (AFIS) forms a collective zone of proximal development (Vygotsky, 1978; Engeström, 1987): examiners work with 
entirely digital materials, novel analytical and manipulative instruments and collectively share stages of the work process. In conjunction with enabling more specific and sharper analysis of latents, there also emerge new challenges and biases. Traditionally, individual work is being collectivized in a way that affects professional objects, rules of activity, examination communities and mutual division of labor (Engeström, 2001). Such transformations collectivize fingerprint examination, requiring the examiners to share the process and justify their decisions. Rather than working with their own personal case, the examiners work with shared cases in a way that requires them from the very beginning to integrate their efforts with those of their peers. Collectivization of examination tends to make diverging personal intuitions, conflicting interpretations, and poorly justified decisions highly visible. In order to productively share their expertise, the examiners have to cultivate relational expertise; they need to understand motivation, thinking and decision making of their peers (Edwards, 1995). They also need to cultivate joint conceptions for articulating their partially implicit knowledge and to develop sufficient common knowledge for sharing knowledge across heterogeneous practices (Edwards, 2012). Collectivized examination practices require examiners to rely on more transparent and collaborative rules of examination.

The present study addresses rules for examining fingerprints in the context of moving to a digitalized examination process which makes the process more transparent and collective in nature. The above described transformations are changing collective methods and practices in fingerprint examination in ways that may be understood in terms of changing social rules and norms of activity. Following Schatzki (1996, 2002), practices of fingerprint examination may be understood as rule-governed forms of repeated social actions. Fingerprint examination may be seen to rely on internalized and, as the above studies suggest, often unconsciously followed and traditionally local personal and social rules. In order to be reliable, however, fingerprint examination has to rely on explicit norms corresponding to international standards of examination, instead of local and idiosyncratic ways of working. The examiners need to base their efforts solely upon task-relevant information so that ill-founded background assumptions or local traditions do not color examinations and associated decisions.

In a digitalized environment, it is thus critical that communities of fingerprint examiners work out shared norms and standards that individual examiners deliberately follow, even in complex cases. The problem is, however, that any rule can be followed in an infinite number of ways in practice (Wittgenstein, 1953). Professional conduct is thus challenging because even agreed rules do not provide actors specific instructions regarding how those that should be followed in a situation. Instead, rules appear to be context-dependent in nature, meaning that professionals utilize them interpretatively for constructing their sense of appropriate behavior in any concrete situation (Heritage 1984; Leiter 1980). When encountering atypical and ambiguous cases, rules may need to be bent or broken, or an agent may otherwise unintentionally fail to follow the rule. Organizational efforts are thus needed for collaboratively agreeing on norms and regulations of examination and for creating policies and standards of appropriate practices aiding investigators' shared efforts and guiding justification of their decisions. When agreeing about rules of organizational activity, it is in principle possible for members of a workplace community to "grasp that rule and judge when it is being correctly followed" (Winch, 1958).

\section{Challenges of organizational learning in the Forensic Laboratory of the National Bureau of Investigation in Finland}

The present study addresses the process of constructing and re-forming rules of fingerprint examination in the context of the Forensic Laboratory of National Bureau of Investigation (NBI) in Finland. New technologies and extensive digitalization with quality and transparency requirements have given NBI important direction to develop fingerprint examination toward a more appropriate, 
transparent, and coherent process. In addition to the changes previously described, digitalization has raised new challenges with different kinds of tools, practices and training provided by equipment manufacturers. Just before 2010, leaders of the Forensic Laboratory of NBI became aware of the need for improvement in the areas of documentation and decision making in the digital examination process. There was a pressing need to harmonize visual and written documentation to ensure the quality of the examination, but also to develop the new investigative process further. Many aspects of prevailing practices of documenting and archiving investigations changed. These changes have not only been related to altering customer requirements but also emerging international quality standards and guidelines. As much of the content of these discussions originated from the international guidelines and best practices developed by global professional organizations as well as by manufacturers of instruments used in fingerprint analysis, this process can be regarded as an instance of adapting international standards in the Finnish forensic context. Having emerged on the basis of international normative pressures for conformity (DiMaggio \& Powell 1983), the recreation and institutionalization of rules can be seen as an organizational activity designed to enhance the quality of the investigative practices and to increase consistency of judgments across individual cases of fingerprint examination.

Although examiners are given regular training regarding the emerging criteria and guidelines of examination, they cannot develop collectively shared rules of examination without iterative joint efforts. This was the motivation behind organizing a series of developmental seminars to reflect on the emerging examination practices. The Forensic Laboratory took a proactive role in developing new kinds of investigative processes, tools and instruments as well as documentation of expert work. This can be conceptualized in terms of organizational learning where the Forensic Laboratory sought to develop coherent procedures to guide its professional activities, including decisionmaking criteria and documentation, so as to meet the new quality requirements of fingerprint examination and to solve practical problems encountered in its activities. The laboratory organized a set of developmental seminars for making the prevailing work processes of individual investigators socially analyzable and discussable. The participants were engaged in reporting the current basis of their practical judgments (see Mustonen et al. 2015) and tried to agree on a shared set of rules that would eventually be included in the organizational code of practice.

The focus of this study, developmental seminars, represented the Forensic Laboratory's efforts to further develop fingerprint process, documentation and decision making and to render the decisionmaking criteria more transparent and coherent. The study focuses on examining joint discussions during the seminars so as to examine how the examiners talked about their analytical practices and developed shared concepts and rules for assessing their investigative processes. To achieve this, the study asks the following questions:

1. What kinds of shared criteria and rules of fingerprint examination were co-constructed during the seminar?

2. What kinds of developmental challenges emerged from digitalization of collective fingerprint-examination process?

\section{Methods}

\subsection{Research setting and participants}

The National Bureau of Investigation (NBI) operates under the Ministry of the Interior as a part of the Finnish public administration. NBI has an important role in Finland producing services for the police and public authorities in charge of law and order. NBI is divided into divisions of criminal 
investigation, criminal intelligence and Forensic Laboratory. The main body of the Forensic Laboratory's mission is to provide forensic services, such as the fingerprint and DNA analysis, to the law enforcement officials in crime investigation. In 2015, there were about 126 experts working in different specialties.

As a part of developing the fingerprint examination, the Forensic Laboratory organized during 2011 a series of 10 three-hour developmental seminars analysed in this article. Altogether, 15 examiners specializing in working with fingerprints participated in these seminars. The first author of the present article, who was responsible for developing fingerprint examination practices and quality criteria at the Forensic Laboratory's fingerprint group, chaired the sessions and designed the meetings.

\subsection{Data acquisition}

The aim of the seminar was to organizationally harmonize the work processes, decision-making criteria and documentation practices of the individual fingerprint examiners. An important aim of the seminar was also to discuss the rules and methods of fingerprint identification and to develop them further so as to institutionalize them into the laboratory's official code of conduct. Examiners were thus encouraged to verbalize their intuitions, thinking, actions, and associated rationale as well as reflect on the nature of their expertise so as to facilitate collective understanding. Examiners were also encouraged to discuss their divergent perceptions, impressions and decisions associated with the latents, and develop new definitions and investigative methods to be used in the work. Further, an important aim of the seminar was to learn to discuss individual examination practices, socially share one's expertise, and constructively reflect on disagreements and diverging interpretations.

The seminar was structured according the examiners' wishes; also the chairperson's emphasis on collective knowledge sharing and making all examiners' voices equally heard shaped the nature of the meetings. The chairperson suggested the main themes and aims of each session and designed pre-tasks for the participants with the assistance of fingerprint examiners (Table 1). The seminar addressed general issues at the beginning and moved toward more focused and detailed ones at the end. The chairperson documented the participants' discussions, opinions, proposed definitions, and decisions during the seminar to PowerPoint slides. She did not take a constitutive part in decisionmaking about the rules, criteria, process and documentation but encouraged and challenged the participants to reflect on the existing processes and to reveal their interpretations of latents as well as the decision-making criteria used in the analysis.

All the developmental seminars were audio recorded. Those sessions that were central from the point of view of the topic of this article, were transcribed word for word, and those that more remotely touched upon the analytical themes were transcribed selectively, focusing only on those sections that related to the analytical themes under investigation. In addition to these, all PowerPoint slides that were either used or prepared during the seminar were included in the analysed data set. These slides included examiners' viewpoints that were presented in the seminar as well as jointly agreed changes concerning the rules, procedures and processes of fingerprint analysis. Furthermore, quality reports as well as LIMS and AFIS documentation were used as research data. Quality reports obtained from LIMS comprised analysed fingerprint images with colour-coding and AFIS-screenshot documentation together with written descriptions of justifications of decisions regarding the identification process. Table 1 provides a summary of the research dataset and its main contents. 
Table 1. Description of the data analysed.

\begin{tabular}{|c|c|c|c|c|c|}
\hline Seminars & Topic of seminar & Pre-task & $\begin{array}{c}\text { Duration } \\
\text { minutes }\end{array}$ & $\begin{array}{c}\text { Pages } \\
\text { and } \\
\text { Words }\end{array}$ & $\begin{array}{c}\text { PowerPoint } \\
\text { Slides }^{1}\end{array}$ \\
\hline I & $\begin{array}{l}\text { Orientation to the set of } 10 \text { seminars. } \\
\text { Different international and forensic conclusion } \\
\text { models, e.g., likelihood ratio, probability, scale } \\
\text { of conclusions in handwriting examination, } 9 \\
\text { scale conclusions etc. } \\
\text { Discussion and conclusions of pre-tasks } 1 \text { and } 2 \text {. }\end{array}$ & $\begin{array}{l}\text { Pre-task } 1 . \text { Analyse one latent } \\
\text { and make judgment of analysis. } \\
\text { Pre-task } 2 \text {. Analyse and compare } \\
\text { one latent and one fingerprint } \\
\text { with written and color-coded } \\
\text { documentation. }\end{array}$ & 185 & - & 27 \\
\hline II & $\begin{array}{l}\text { Discussion and conclusions of pre-tasks } 3 \text { and } 4 \\
\text { results. } \\
\text { Discussion of pre-task } 5 \text { and } 6 \text { results. } \\
\text { Concluding best practices of using AFIS. }\end{array}$ & $\begin{array}{l}\text { Pre-task 3. Analyse one latent } \\
\text { with color-coding. } \\
\text { Pre-task } 4 \text {. List definitions and } \\
\text { features of "no value" latent. } \\
\text { Send it in advance to chair for } \\
\text { summary for the seminar } \\
\text { discussions. } \\
\text { Pre-task 5. Take latent from the } \\
\text { pre-task 3, process AFIS- } \\
\text { searches with } 3 \text { kinds of pre- } \\
\text { given search criteria (a-c). } \\
\text { Pre-task 6. One examiner's } \\
\text { AFIS-test results. }\end{array}$ & 162 & \begin{tabular}{|l|}
34 \\
7667
\end{tabular} & 98 \\
\hline III & $\begin{array}{l}\text { Conclusion of "no value" latent. } \\
\text { Developmental needs in LIMS process. }\end{array}$ & Material from seminar II. & 180 & $\begin{array}{ll}18 \\
4302 \\
\end{array}$ & 16 \\
\hline IV & $\begin{array}{l}\text { Discussions of quality and clarity criteria with } \\
\text { the help of colors. } \\
\text { Developmental needs in report. }\end{array}$ & Material from seminar II. & 120 & $\begin{array}{ll}13 \\
3053\end{array}$ & 15 \\
\hline V & $\begin{array}{l}\text { Feedback from the field. } \\
\text { Best practices with Photoshop. }\end{array}$ & $\begin{array}{l}\text { Pre-task 7. Two examiners } \\
\text { prepared examples and best } \\
\text { practices of Photoshop. }\end{array}$ & \begin{tabular}{|l|}
67 \\
\end{tabular} & - & 14 \\
\hline VI & $\begin{array}{l}\text { Discussion of articles and implementation of } \\
\text { findings in Forensic Laboratory. } \\
\text { Color-coding examples from real cases and } \\
\text { visual documentation of examiners. } \\
\text { Risks of digital image manipulations. } \\
\text { Concluding the quality and clarity definitions. } \\
\text { Reflection of ACE-V process - visual } \\
\text { documentation and LIMS process. }\end{array}$ & $\begin{array}{l}\text { Pre-task } 8 . \text { Read color-coding } \\
\text { articles. }\end{array}$ & 136 & $\begin{array}{ll}7 \\
1861\end{array}$ & 30 \\
\hline VII & $\begin{array}{l}\text { SWGFAST guidelines and situation in Finland - } \\
\text { what to learn and implement. } \\
\text { Quality assessment report and developmental } \\
\text { tasks. }\end{array}$ & $\begin{array}{l}\text { Pre-task 9. Read and reflect } \\
\text { SWGFAST-guidelines in pairs } \\
\text { with the help of pre-given } \\
\text { questions. Make PowerPoint- } \\
\text { slides. Give presentation of your } \\
\text { cogitation during the seminar. } \\
\text { Read quality assessment report. }\end{array}$ & 167 & - & 72 \\
\hline VIII & $\begin{array}{l}\text { Discussion of discrepancies in practices, process } \\
\text { and documentation in LIMS. } \\
\text { Focusing the discrepancy meetings. }\end{array}$ & $\begin{array}{l}\text { Pre-task 10. Group of } 3 \\
\text { examiners, team leader and chair } \\
\text { made preliminary proposal of the } \\
\text { basis in LIMS process, practices } \\
\text { and documentation. }\end{array}$ & 173 & $\begin{array}{l}9 \\
1894\end{array}$ & 19 \\
\hline IX & $\begin{array}{l}\text { Proposals of groups and concluding } \\
\text { developmental actions in LIMS and } \\
\text { documentation. } \\
\text { CTS test results. }\end{array}$ & $\begin{array}{l}\text { Pre-task 11. Group A. Proposal } \\
\text { of new process and } \\
\text { documentation in LIMS } \\
\text { Pre-task 12. Group B. } \\
\text { Propositions of new process and } \\
\text { documentation in LIMS. } \\
\text { Previous material. } \\
\end{array}$ & 168 & $\begin{array}{ll}16 \\
3873\end{array}$ & 26 \\
\hline X & $\begin{array}{l}\text { Aims and goals of the developmental seminar. } \\
\text { Feedback and common discussion. }\end{array}$ & - & - & - & 19 \\
\hline \multicolumn{3}{|c|}{ TOTAL } & 1358 & $\begin{array}{l}97 \\
22650 \\
\end{array}$ & 336 \\
\hline
\end{tabular}

Note 1: This includes both prepared materials and notes summarizing the contents of discussion. The latter were jointly constructed during the seminars. 


\subsection{Data analysis}

The data analysis was focused only on those seminar sessions that were relevant for the purposes of the present study; general discussions on professional development, organisational issues and treatment of specific documentation (e.g., SWGFAST guidelines) were excluded. Accordingly, sessions 2, 3, 8 and 9 were selected to be transcribed word for word. Sessions 4 and 6, on the other hand, were chosen to be transliterated selectively, focusing on the specific topics discussed in them. The length of the meetings varied from 67 to 185 minutes, totalling altogether 1.358 minutes $(22 \mathrm{~h}$ $63 \mathrm{~min}$ ) of audio recordings (96 transliterated manuscript pages in total). During all the seminars, 336 PowerPoint slides were produced. Some of the slides were used in the sessions to assist the chairperson to introduce themes for discussion to the participants, others reported the results of the participants' pre-tasks or documented the jointly achieved results of the discussions. The transcribed data were analysed according to procedures of qualitative content analysis (Saldaña, 2012; Krippendorf, 2013). To ensure reliability and validity of the analysis, the authors read through all the data several times and defined central themes and important issues present in the seminar discussions. All authors took part in all aspects of the analysis.

The transcribed data were uploaded to ATLAS.ti software in which a transcription of each seminar session constituted a primary document of its own. During the analysis, the authors examined main themes of discussion and traced the issues addressed by the participants both in text and by utilizing the PowerPoint slides that documented the shared understandings regarding criteria and rules of assessing quality of latents as well as development of shared practices of organizing the analytic process. Specifically, the following themes of discussion were chosen for detailed analysis: 1) criteria of no-value fingerprints, 2) color-coding of latents, 3) practices of using AFIS and LIMS systems and documenting the fingerprint examination process in them and 4) division of labour between examiners during the fingerprint examination process. Some data were eliminated from the analysis because of ambiguous content or rare and unsystematic occurrence. After detailed coding of the seminar transcripts, the categories were systematized according to two closely related analytical "families", those of 1) rules and criteria as well as 2) technical tools and division of labour among the examiners. The complementary bodies of data (other transcribed discussions, PowerPoint slides, pre-tasks, LIMS and AFIS documentation, self-assessments) were used to support the data analysis.

\section{Results}

\subsection{What kinds of criteria and rules of assessing quality of fingerprints were co-constructed during the seminar?}

Defining criteria of no-value fingerprints

In the past, Forensic Laboratory followed the international quantitative standard which required 12 certain minutiae in a fingerprint to qualify for an identification. In 2001, however, the laboratory changed to a holistic approach, which was an international trend at the time. Within the holistic framework, the laboratory had defined some general guidelines according to which the analysis of latents was to be conducted. The guideline for assessing the value of fingerprints was as follows: two fingerprints should be regarded as identical when such concordance was achieved between them in terms of the amount and importance of their corresponding details that ruled out coincidence and demonstrated that there remained no inexplicable differences. This principle was so generic in nature that it did not provide fingerprint examiners with a guideline that was concrete 
enough to decide on identification or non-identification of latents; consequently, the decisionmaking remained individualized and idiosyncratic in nature (Mustonen et al. 2015).

At the same time, the international fingerprint-community had developed standards for fingerprint analysis based on the ACE-V (Analysis, Comparison, Evaluation and Verification) method (Ashbaugh, 1999). The method directed and shaped many aspects of the fingerprint examination and provided an associated frame of reference. It, for instance, guided examiners to carefully analyse latents and identify details and distortions across the examination process (see Maceo, 2009; Mustonen et al. 2015). During the comparison and evaluation phases, the details and distortions were compared to another fingerprint so as to decide whether or not the latent could be identified. In the case of possible identification in the verification phase, another examiner reprocessed the examination of the latent in question and made a decision. At the time of this study, however, the ACE-V method was not completely implemented in the Forensic Laboratory's work practices. There was no common agreement among the fingerprint examiners about the rules and criteria to be used in the analysis; that is, the work was done in an individualistic manner with neither established criteria for an identification nor for a no-value fingerprint (Mustonen et al. 2015). The focus of the seminars analysed here was thus to collectively discuss and define a new set of rules that could be institutionalized into organizationally-defined written guidelines for future application.

To raise awareness among the examiners about the need to establish shared rules of fingerprint investigation, the seminar series started with a set of the pre-tasks, the results of which were discussed in the sessions I and II. The results revealed that different examiners concentrated on slightly different areas of the test fingerprints when analyzing them as well as determined different amounts of special detail in the images. Some of the examiners analyzed the fingerprints in full, meaning that they paid attention also to the edges of the images while others focused their work on the central parts only. On the basis of one of the pre-tasks, one examiner suggested decision-making criteria for fingerprints that were of no value in the analysis. According to this proposal, three categories could be established; fingerprints with 0-4 special details were to be regarded as no value, those with 5-8 possibly identifiable, and those with 9 or more identifiable.

The suggestion is evidence, that despite the quantitative criteria for the determination of the boundary between no-value and identifiable latents had been discarded ten years prior to the seminar, they still figured as a historically effective stage in the actual fingerprint assessment process. At the time of the seminar, there was, however, no clear understanding among the examiners about the number of special details required for categorization of latents; the issue was subject to individual variation, as exemplified by the following discussion. In response to the chairperson's question about the level of generality with which the criteria of no-value fingerprints should be defined the examiners said:

\section{Data excerpt 1:}

Examiner A: If there is lot of other information and only 4 minutiae, a report [i.e., identification] can still be written. [But] there must be lot of other information.

Examiner B: Or [there may be] a very large palm print with 9 minutiae only, but nothing else.

Examiner A: There can even be as many as 15 minutiae, but in a manner so scattered that it is impossible to build any connections between them. Then it [the fingerprint] is of no value for anything. 
To move on in the discussion from the initial suggestion cited above to the conclusion concerning the criteria of fingerprints of no value, the chairman asked the examiners to explain the qualities of those latents that were completely useless for analytical purposes. The examiners characterized these fingerprints as follows:

\section{Data excerpt 2:}

Examiner B: A latent, where there are only Level 1 details ${ }^{1}$, only flow of ridges. [Then] one cannot say if it [the print] is of a finger etc., whether it is a loop or what?

Examiner C: Sometimes one encounters prints with traces from work gloves. [A useless fingerprint would be] at least one with no ridge flows at all.

Examiner D: Also in a ten-print card one can have so strong a pressure that nothing can be seen (...), no pattern type.

While this discussion continued, the chairperson composed questions and drafted a tentative list of the criteria of no-value latents on the slides while the examiners commented on them:

\section{Data excerpt 3:}

Chairperson: What if there was a group of pores and they were close each other? Would it be enough to have a 10 pore group?

Examiner A: ... or if they are close to one another, three over there and two there.

Examiner B: I would say that it is not enough. I think we should write it, [it's] what we really can do [in practice] and not in theory.

Examiner C: The location of the pores may be [the criteria] that can we use, not the shape of the pore. Perhaps, a more important issue [is] the structure of the ridge, how the ridge ends or curves $(\ldots)$.

This sort of a joint construction of criteria for no-value latents continued for a long period of time with specific focus on different aspects of palm prints and fingerprints with occasional references to the technical means of extracting latents from crime scene. The discussion also revealed the fact that although examiners were experienced professionals, they had problems in verbalizing their analytical practices and visual decision-making criteria. As noted by Examiner F during the debate: "Here we can see that everything is in our heads, but how can we verbalize it ...". "A bit later Examiner E backed up Examiner F by saying, "we all acknowledge these criteria, but putting them to paper is hard (...) This was quite a push!"

As a result of the seminar session III, the fingerprint examiners succeeded in putting into words their joint understanding of the criteria that determined the category of no-value fingerprints, that is, latents that were not useful in any kind of investigation. This formulation remained tentative, however, as the examiners also agreed upon the fact that exact or well-specified criteria cannot be fully articulated. On the basis of the pre-assignments and ensuing discussions, the definition of novalue latents was consensus solutions proposed by practitioners and collectively summarized into the following criteria.

\footnotetext{
${ }^{1}$ Level 1 special detail includes the presence of the general ridge flow and pattern configuration; Level 2 involves the presence of individual types and positions of formations, such as a ridge ending, bifurcation, dot, or combinations thereof; and Level 3 all attributes of the accidental characteristics and intrinsic ridge formations, such as ridge path deviation, width, edge shape, pores, breaks, creases, scars and other permanent details affecting individual ridges as well as the proportion of and interrelationship between these minutiae.
} 
1. There were no clear special details or friction ridges visible;

2. Even if the friction ridge pattern was visible, one could not say whether the image was a fingerprint, palm print or foot print (analysis could be done if the quality of the print was poor with interferences of dust, grease or other distortions, and with no special details visible in the latent);

3. There existed 0-4 minutiae only;

4. Pattern type was visible but no other information;

5. No Level 3 special details were visible;

6. Special details were so unclear, scattered or tangled that they could not be compared and connected with one another;

7. Structure of the friction ridges was discontinuous or broken, and the position of the minutiae could not be accurately determined;

8. There existed overlapping prints and lateral movement of a print, and the prints could not be differentiated from one another;

9. The size of a latent was so small that there were no individualizing special details; and

10. Delta, skin folds or friction ridge pattern was not visible (in the case of palm prints).

As is evident, the rules constructed and agreed upon by the fingerprint examiners were much more detailed than the existing ones at the time of the study. Earlier, the guidelines had not been officially given by the NBI but had been drafted by an individual fingerprint examiner who was in charge of the methods in the fingerprint group. Once the rules, whose construction has been analyzed here were given final formulation, they were institutionalized in the form of formal organizational instructions at the Forensic Laboratory and incorporated into the laboratory's quality system, thereby forming a policy for individual examiners.

\section{Constructing criteria for color-coding}

In addition to the criteria of no value fingerprints, the seminar aimed at developing rules concerning clarity and colour coding of latents. As noted earlier (Mustonen et al. 2015), the examiners were recommended to use Photoshop software to make precise codings and annotations to latent images during the analysis. This was done by marking minutiae or ridge flows with the so-called GYRO colours, where green stood for clear, good quality minutiae, yellow for mediocre, red for uncertain and orange for minutiae marked during the fingerprint-comparison stage (see Langenburg \& Champod, 2011).

As revealed by our earlier analysis (Mustonen et al. 2015), the practice of colour coding the minutiae was highly inconsistent among the fingerprint examiners. Some examiners did not use colour-coding at all, but wrote verbal reports about how many minutiae they had found when analysing the latents and comparing them to ten-print cards. Others followed the recommendation of marking minutiae with colour codes but did so in a highly individualised manner, which revealed that colour coding involved the situated constitution of new knowledge rather than governance by explicit and well-understood rules of practice. Because fingerprints are information-rich research objects, it was natural for the examiners to identify different minutiae in different ways. This situation was also implicitly accepted by the Forensic Laboratory as it did not enforce any formal organizational rules about colour coding of special details in its quality instructions.

To make the above-mentioned situation visible and recognizable, and to motivate examiners to critically scrutinize their investigative practices, the participants were given a pre-task where they 
were asked to analyse one challenging latent and document their results with the help of written annotations and colour coding. The results of the pre-task are presented in Table 2 below.

Table 2. Results of the pre-task number 3 with color-coding of minutiae. The pre-task was accomplished anonymously and the numbers mentioned in the first column refer to individual examiners whose identity was not revealed during the seminar.

\begin{tabular}{|c|c|c|c|}
\hline Examiner & $\begin{array}{c}\text { Number of coloured minutiae: } \\
\text { green }\end{array}$ & $\begin{array}{c}\text { Number of coloured minutiae: } \\
\text { yellow }\end{array}$ & $\begin{array}{c}\text { Number of coloured minutiae: } \\
\text { total }\end{array}$ \\
\hline 1 & 7 & 11 & 18 \\
\hline 2 & 16 & 3 & 19 \\
\hline 3 & 18 & 6 & 24 \\
\hline 4 & 13 & 4 & 17 \\
\hline 5 & 13 & 6 & 19 \\
\hline 6 & 11 & 7 & 18 \\
\hline 7 & 11 & 3 & 14 \\
\hline 8 & 13 & 4 & 17 \\
\hline 9 & 7 & 11 & 18 \\
\hline
\end{tabular}

As is evident in Table 2, the decisions concerning colour coding of minutiae differed from one examiner to another: the amount of minutiae marked ranged from 14 to 24 and a similar kind of variance took place regarding the location and amount of special details coloured with green and yellow. Some examiners carefully marked creases and scars while others did not. Moreover, color coding of good areas used in comparison and weak areas that could not be used for such purposes varied significantly. All this indicated that the examiners lacked a shared basis of interpretation and marking of the minutiae. The pre-assignment thus fulfilled the basic purpose of motivating the examiners to take a closer look at their work practices but did not provide a perspective on what might be behind the differing end-results.

The seminar sessions III and IV were devoted to the tentative reflection on the results of the pretask. The discussion revealed that each examiner had technically modified the fingerprint so as to make it easier to analyse. This had been achieved by using a variety of functions provided by Photoshop software, such as enhancement or levels tool. Also the way of extracting the fingerprint from the crime scene affected the clarity of the image. Furthermore, the decisions concerning the ways in which the images were manipulated affected the examiner's ability to recognize special details, as was explained by Examiner B:

\section{Data excerpt 4:}

The first one is mine, with seven greens. First I did this and then looked from AFIS, and I wanted to change yellows to green, but I did not do that. It [the image] was so much better in AFIS. I made it too dark there, but I did not bother to do it again. Sometimes [there is] too much contrast.

The practices of manually marking the special details also differed from the way in which the automatic coding function of the AFIS system operated. For different types of special details, AFIS marked them differently. Some examiners tried to follow the practice explained to them in training courses by the AFIS producer's trainer, but others did not follow the guidelines and placed colourings in a manner differing from that recommended. This created confusion during the interpretation of the markings in the seminar. When it comes to the details the examiners had decided to colour-code, the practices differed as well. Although the minutiae the examiners marked were mostly the same, the colours differed: "The greens and yellows changed quite a bit" (Examiner A). This notion was later substantiated with the help of an example: 


\section{Data excerpt 5:}

Examiner A: If you see, that there come three ridges upwards and two comes after a small kind of spread [fuzzy/distributed] own; is it yellow or green? You know, that there is definitely a minutia, but you do not know whether it is here or there. Quite often you mark it as a yellow.

After the inventory of the interpretative practices concerning colour coding, the examiners moved on to define the rules of coding, which took place in the sessions IV and VI. In a similar vein as with the no-value fingerprints, the discussion was facilitated by collecting the remarks made on the basis of the pre-assignment in slides and asking participants to suggest how to define when to use green and yellow. Chairperson collected the comments and put them together in a form of a suggestion which was presented in a slide. According to it, green indicated a clear, definite special detail, yellow relatively clear detail, and red contradiction, which was found when two colourcodings were compared in a later stage of fingerprint examination. The discussion proceeded then to articulate concrete criteria according to which clarity of a fingerprint could be understood. Thus green was defined to refer to friction ridges that clearly continued with a third, ending friction ridge in between them. Another case of a clear green minutia was a friction ridge, which ended or bifurcated for sure, in addition to which other clear instances found in the fingerprint were to be marked with an arrow, delimiting the area in question with a line, or marking the area with transparent colour. Yellow, in turn, was defined to mean disturbances in the print or in the surface from which it had been extracted (e.g., deposition or pressure distortion, trash, dust, sweat, grease), or unclarity of the continuation or ending of a friction ridge. Red was defined to picture the area of inexplicable discrepancies. Finally, blue was added as a new colour code to be used for those marks that were not to be regarded as special details but still had some significance from the point of view of the analysis. Among these were signs of tape and biological marks such as scars, scratches and folds of skin.

In summary, the discussions in the seminars revealed that fingerprint analysis was a very complex and challenging process and seminars could not solve all the problems that had been encountered in defining the rules to be used in the analysis. However, fingerprint examiners verbalized their perceptions and interpretations and ended up in defining rules which they collectively accepted. Furthermore, the Forensic Laboratory found the discussion useful and decided to use the results of it in the further development of the examination practices. More importantly, the Forensic Laboratory decided to include some of the rules created during the seminar in its new operational guidelines.

\subsection{How did digitalized examination practices affect the fingerprint examination process?}

In addition to the rules concerning categorization of fingerprints and marking special details found in them, the seminar addressed the ways in which tools and instruments should be applied during the work processes. The article will next analyse how the rules for using tools were negotiated and then focus on the development of the work processes in fingerprint examination.

The introduction of new digital tools, i.e., AFIS and LIMS, gave rise to new transparency and accountability requirements related to the new quality system appropriated. Consequently, there emerged a need to develop and determine the documentation rules between AFIS and LIMS, and to integrate this with other software, such as Photoshop and Word. The seminar therefore aimed 1) to find the best practices of working with AFIS that were used as a system of digital fingerprint 
storage and matching as well as 2) to develop practices of using LIMS where the examiners recorded their analysis, justifications and decisions during the examination process. An aim of the seminar was also 3) to implement the fingerprint examination framework known as ACE-V (see section 5.1) into work practices, creating more specific documentation, improving coherence (uniformity) of investigation, investing efforts to more adequate targets, pursuing further development of quality work, and improving overall meaningfulness of the research activity.

\section{Developing practices of using tools and instruments}

In order to make the challenges of tool use visible, the participants were asked to independently carry out AFIS searches with pre-given search criteria and a latent before the seminar session II. The examiners were requested to send the chairperson screenshot documentation of each task they had conducted; documentation from AFIS-codings with search criteria, a list of candidate fingerprints given by AFIS, and their decisions of hit or no hit. The pre-given AFIS-search criteria were: 1) to do auto coding of the latent without pattern type, without determining specific finger, delta and core, and without a need to do comparison for candidates; 2) to do coding of the latent with examiner's own best practice as employed during in his or her normal work process, including comparison with registered fingerprint and a list of all the candidates found, and 3) to do auto coding with pattern type, specific finger, delta and core.

While using AFIS in fingerprint analysis, the examiners could decide whether to apply the auto coding function of the device or not. As stated in the first pre-task defined above, the examiners were asked to perform the task with auto coding. The aim of this was to facilitate the participants' efforts to discuss and make explicit the collective understanding of the risks and quality issues of the AFIS search process.

Data excerpt 6:

Examiner E: There has been a case where a person [an examiner] has first got a hit and then had not got it again for another time.

Examiner B: It was, indeed, [pointed out] in our training that changing even one minutia may lead to "jumping" of a candidate, resulting in change in the candidate list.

(...)

Examiner B: I once had such a latent, which got a hit and then I messed up something. I did it again, [but] did not get it into the list of 100 [fingerprints]. Well, [I] just use[d] a half of the day for that...

\section{Data excerpt 7:}

Examiner B: ...that is, if you measure [with AFIS measurement tool] it in a wrong way, you cannot find it ever again.

Examiner E: Right, that is an important factor.

(...)

Examiner E: We surely miss [hits], because of wrong measurements.

The excerpts cited above reveal that the use of auto-coding function in AFIS involves challenging risks of analysis. The examiners were very aware of these kinds of uncertainties built into the AFIS searches and results, and the discussion demonstrated only a small part of the dilemmas of using AFIS which the examiners had learned of. The discussion concerning the examiners' own best practices of doing fingerprint analysis revealed, for instance, that some examiners eliminated all 
automatic codings in AFIS and did everything manually, whereas others relied on those codings. Corresponding divergence was also noticed in the seminar with respect to specifying AFIS searches for determining delta and core.

In addition to the choice of using or not using the auto-code function, the examiners were also able to choose which fingers they specified in AFIS when doing the search and analysis. Pre-assignment 5 was designed to bring out the variance between individual examiners in this respect. As illustrated in Table 3 below, the pre-task revealed that the strategies of carrying out searches with AFIS varied: some examiners used only two fingers whereas others used all ten, and many between those two extremes.

Table 3. Pre-task 5: AFIS search with own criteria

\begin{tabular}{|c|c|c|c|c|c|c|c|c|c|c|}
\hline EXAMINER & ${ }^{1}$ RF1 & RF2 & RF3 & RF4 & RF5 & LF6 & LF7 & LF8 & LF9 & LF10 \\
\hline $\mathbf{1}$ & & $\mathrm{x}$ & & & & $\mathrm{x}$ & $\mathrm{x}$ & $\mathrm{x}$ & $\mathrm{x}$ & \\
\hline $\mathbf{2}$ & $\mathrm{x}$ & $\mathrm{x}$ & $\mathrm{x}$ & $\mathrm{x}$ & & $\mathrm{x}$ & $\mathrm{x}$ & $\mathrm{x}$ & $\mathrm{x}$ & \\
\hline $\mathbf{3}$ & & $\mathrm{x}$ & & & & $\mathrm{x}$ & $\mathrm{x}$ & $\mathrm{x}$ & $\mathrm{x}$ & $\mathrm{x}$ \\
\hline $\mathbf{4}$ & & $\mathrm{x}$ & $\mathrm{x}$ & $\mathrm{x}$ & $\mathrm{x}$ & $\mathrm{x}$ & $\mathrm{x}$ & $\mathrm{x}$ & $\mathrm{x}$ & $\mathrm{x}$ \\
\hline $\mathbf{5}$ & & $\mathrm{x}$ & & & & & $\mathrm{x}$ & & & \\
\hline $\mathbf{6}$ & $\mathrm{x}$ & $\mathrm{x}$ & $\mathrm{x}$ & $\mathrm{x}$ & $\mathrm{x}$ & $\mathrm{x}$ & $\mathrm{x}$ & $\mathrm{x}$ & $\mathrm{x}$ & $\mathrm{x}$ \\
\hline $\mathbf{7}$ & $\mathrm{x}$ & $\mathrm{x}$ & $\mathrm{x}$ & $\mathrm{x}$ & $\mathrm{x}$ & $\mathrm{x}$ & $\mathrm{x}$ & $\mathrm{x}$ & $\mathrm{x}$ & $\mathrm{x}$ \\
\hline $\mathbf{8}$ & & & $\mathrm{x}$ & & & $\mathrm{x}$ & $\mathrm{x}$ & $\mathrm{x}$ & $\mathrm{x}$ & $\mathrm{x}$ \\
\hline $\mathbf{9}$ & & & & & & & $\mathrm{x}$ & $\mathrm{x}$ & $\mathrm{x}$ & \\
\hline
\end{tabular}

Note 1: RF=right hand finger, LF: left hand finger

These differences in using AFIS gave rise to a detailed discussion about the role of automatic coding in the analysis as well as how and in what way it should be used, finally ending with the question of whether or not the coding should be done in accordance with the way the tool actually did it. During the debate, it was proposed that the coding should be done as it has been taught in the training sessions organized by the instrument manufacturer which all of the examiners have attended. One thing that seemed to have clear influence on how the analysis should be done had to do with the properties and technical workings of the tool; that is, the examiners considered it important to know how the procedure of coding in AFIS works, or how AFIS "thinks", in the words of one of the participants.

\section{Data Excerpt 8:}

Examiner G: Here it would be good for us to learn to think how AFIS works, [so that] we would learn to do the coding in a same way as AFIS does it. Just like (...) it was said in training. (...)

After a detailed discussion of how and when the automatic coding should be applied and how many fingers should be used in the analysis, the actual practice of automatic coding and its meaningfulness, including the reliability of AFIS searches, was addressed. This conversation focused on the issue of how the examiners' ways of coding the latents affects the results of the AFIS search. One of the examiners had done tests with the latent used in the pre-task 5 with more detailed search criteria and strategies. The examiner also shared his knowledge of the practices of using AFIS tools, such as auto coding, cropping, equalization and using threshold, as well as his results achieved by using different search strategies. Demonstrations like this revealed further variations in the search results and gave rise to a discussion about how the searches and relating 
coding should be done. These results were jointly discussed, and the best practices of making the searches (e.g., with or without defining left or right hand, pattern type, core or delta) were defined. The discussion based on the pre-tasks of AFIS use thus supported the collective clarification and unification of the ways of conducting the AFIS searches. The talk also resulted in defining the shared procedural rules for using AFIS; it was decided that these would be added to the organizational guidelines of analysis.

In addition to the rules and practices of using AFIS, other tools were also discussed in the seminar. The examiners used Photoshop for enhancing and highlighting (color coding) fingerprint images. The seminars' discussion revealed that as was the case with AFIS, the participants' practices of using Photoshop varied substantially. Using Photoshop was voluntary; thus some examiners rejected it and marked minutiae using AFIS only. Some examiners, on the other hand, had advanced skills in Photoshop. They used its features in flexible and multi-faceted ways. In order to elicit the old-timers' skills and competencies, sophisticated ways of using Photoshop were jointly practiced. It was agreed that in cases of poor latents, Photoshop should be utilized so as to document the examination process. It was also concluded that moving from manual to digitalized examination process challenged the whole community's competencies and required systematic collective efforts to come up with new workable practices.

The discussions of the seminar highlighted the individual differences in using tools and instruments as well as differences in individual workflow processes. Further, the negotiations during the seminars aimed at explicating the rationale behind individuals' ways of working and, thus, constructing a shared view of rules and criteria for the work processes and use of tools. It was jointly agreed that the transformation toward the digital era has truly challenged the field of forensic examination. The discussions also confirmed the significance of training and the need for unity in the analytical processes in fingerprint examination to solve the issues of transparency and reliability.

\section{Developing workflow processes}

Beyond the shared procedures of operating central investigative instruments, the seminars also revealed tensions regarding the variety of information systems used. It was considered problematic that AFIS and LIMS software were not integrated with one another. Also some documentation practices were discussed and considered problematic; for example that examiners had to repeatedly enter same information into different places with different tools and varying operational procedures. This discussion was mainly triggered by the fact that information entered to AFIS did not automatically transfer to LIMS but had to be re-entered, participants felt the need for to reconsider the documentation practices. The attention to workflow processes and the division of labor (see Mustonen et al. 2015) discussed in the seminars was strongly connected to the documentation and distribution of tasks across different examiners. It was considered necessary to agree about roles and tasks of examiners taking part in different stages of analysis.

During seminar VIII, the discussion focused on developmental needs between work roles, processes and documentation. In order to provide background material for orienting the examiners to the topic, the chairperson, team leader and three examiners made a proposal (pre-task 10) on the LIMS process and associated documentation. During the seminar, the examiners raised many concerns about their roles and the division of labor across different stages of investigation that were explicated in the proposal. Further developmental needs were identified as follows: 1) the role and tasks of registration (e.g., between fingerprint group and customer service) and 2) examiners' roles and tasks during the examination process (e.g., between screening and identification). Furthermore, 
new digitalization possibilities regarding the examination process that might influence the workflow processes were identified. Participants also reflected on their knowledge in relation to SWGFAST guidelines. In the conclusion of this session, the roles of the examiners during the LIMS process were recorded. The next step was to divide the participants into two teams that would make their detailed proposals on the development of the work process for the next seminar.

The two teams were set up to analyze the nature of LIMS documentation and the role of phases (pre-task 11 and 12). The role of the teams was to produce "maps" of those LIMS screens that they preferred. Also, the structure of the research report was reflected upon to ensure that relevant information was documented. The documentation was considered to play a crucial role in making each examiner's work visible. If earlier examinations and their justifications were properly documented, it would be easier for an examiner to go back to re-examine a case, if needed. The ensuing discussion will be illustrated below.

\section{Data excerpt 9:}

Examiner F: So, what was the duty of the screener 2 and what other duties were there for the screener?

Chairperson: You really have listed the duties, what is the role of AFIS [and] what are the current practises, haven't you?

Examiner F: Yes, and we tried to look at the process as a whole, so that we could get motivating duties for the examiner 1.

Chairperson: Do you nowadays, in a case of a challenging latent, make a mark on the starting point?

Examiner H: Yes. It is not our purpose to create a situation where the identifier has to guess where to start from.

Chairperson: And when the latent is transferred to the identifier, the minutiae will be deleted?

Examiner H: And when [they are] saved to archive, they will have a look also.

Examiner F: We put down issues here which would inhibit the progression of the examination. If these were made at the same time, [the person] would be able to go on smoothly.

One of the puzzling features of existing information systems that had an effect on the workflow was that screen shots of AFIS or Photoshop could not be directly transferred to LIMS, either automatically or manually. The documents needed to be first stored in Word and then linked to LIMS as attached files of the case. In many situations, information had to be re-entered several times, which decreased the examiners' motivation to document their activity:

\section{Data excerpt 10:}

Examiner B: How we record to LIMS? If you make the written documentation, why should we also fill this up? I do not understand, that we document the same things in LIMS and to this work report.

When a case was finalized, the documentation was distributed across several information systems, i.e., AFIS, LIMS, Photoshop and a shared network folder. As the systems were not optimally integrated, it was critical to collectively reflect on diverging work practices and draft shared operational procedures. The examiners thus reflected on the appropriate place of the documentation. They also discussed what kind of documentation should be done when using different information 
systems. For example, what should the content documented in AFIS be, and should it be focused on the analysis of the latent, and how was that related to the information stored in LIMS.

\section{Data excerpt 11:}

Examiner B: I would like to use either AFIS or LIMS so that a part of the information would not be in AFIS and another part in LIMS, I would record clearly in one place.

Examiner H: Yes, how to decide, of course, as little as possible.

Examiner C: If it is documented in AFIS, another examiner who looks at the fingerprint will see it. If it is in another place, the identifier cannot see it.

Examiner F: Everyone has not done so, there should be a clear line where the information exists.

Facilitated by discussion like the one cited above, the examiners eventually worked out shared practices of documentation. According to the procedure defined in the seminar, LIMS would hold all the relevant information relating to the investigated cases. The identifiers were asked to do all documentation, including the research report, to LIMS. In the research report, it was considered sufficient to have AFIS screen shot of the context of good quality latents. In cases of mediocre and poor quality latents, it was regarded as necessary to do visual documentation in Photoshop with GYRO color coding. Such complete documentation was also agreed to be acceptable if examiners considered it relevant for other reasons.

In summary, the seminar elaborated shared strategies and norms of working with the evolving set of digital instruments. As a result, guidelines of fingerprint examination process and new methodological descriptions had to be created or updated. Extension of guidelines in visual and written documentation to LIMS and AFIS were created. These new rules, roles and methodological definitions were accepted to be added to the Forensic Laboratory's codes of conduct. Many of the encountered tensions regarding digitalized practices of fingerprinting were thus jointly solved.

\section{Discussion}

The present study examined how the fingerprint examiners reflected on and developed their work practices through a series of joint seminars. The seminars aimed at finding new ways of improving the quality of fingerprint examination according to national and international requirements and, thereby, also assisting the community to proactively orient toward future challenges of forensic investigation. The authors of this article analysed transcripts of the audio-recorded seminar sessions, examination tasks carried out by the examiners, and preparatory and jointly constructed documents. The content-rich material revealed various tensions and limitations regarding the enacted practices of examination as well as a series of co-constructed improvements. Simultaneously, there were certain methodological limitations of the study. Because of the organization's safety policy, we were not able to provide detailed information of the numerous latents that the participants analysed when preparing to the seminar session. Our data collection focused on the seminars so that subsequent steps of developing the operational procedures at the institution were not systematically covered or followed up. Nevertheless, the discussions and other materials revealed many crucial tensions and challenges regarding the prevalent personal and collective practices of investigation as well as jointly constructed improvements of professional procedures. Overall, we maintain that the data provided a sufficient basis for examining the transforming investigative practices of the fingerprint examination community. 
First, our investigation focused on examining shared criteria and rules of fingerprint examination that were addressed and constructed during the seminar. We considered fingerprint examination as a complex rule-governed form of repeated social actions. To adequately analyse information-rich latents with varying detail, such rules cannot be mechanically applied to a concrete case, but require justified interpretation in context. The results thus revealed that the examiners followed personal and local rules that did not appear to be very systematic or well elaborated. The enacted criteria for assessing the value of fingerprints were fuzzy, varied from one investigator to another and involved elements of both outdated and current operational procedures. The practices of identifying minutiae and colour coding indicated similar vagueness and divergence between the examiners. The seminars contributed to further elaboration of the rules of investigation and more explicit criteria of analysing quality. The Forensic Laboratory decided to add some of the operational procedures to its new examination guidelines. These rules, constructed and agreed upon by the fingerprint examiners, were more detailed than those prevailing at the time of the study. Once the guidelines, the construction of which is analysed here, were given final formulation, they were institutionalized in the form of the official organizational instructions approved by the Forensic Laboratory and incorporated into the laboratory's quality system, thereby forming a policy for individual examiners to follow.

Secondly, we examined developmental challenges that emerged from digitalization of collective fingerprint examination process. The seminar discussions confirmed that moving to completely digital practices had challenged examination practices through various tensions, breakdowns, and contradictions regarding the practices of using instruments. The discussions of the seminars highlighted individual differences in using tools and instruments as well as differences in individual work processes. The participants' practices of using AFIS varied a great deal and involved diverging ways of carrying out searches and documenting examination processes. It was considered problematic that AFIS and LIMS were not integrated so that same information had to be repeatedly entered when moving from one system to another. Consequently, there emerged a need to develop and determine the documentation rules between the tools of AFIS and LIMS and to integrate with other associated software, such as Photoshop and Word, so as to ensure the quality assurance, processes and documentation. The negotiations taking place at the seminars aimed at explicating the rationale behind individuals' ways of working and constructing a shared view of rules and criteria for processes and the use of tools. These discussions confirmed the significance of training and need for unity in the processes of fingerprint examination so as to resolve the transparency as well as reliability issues.

The present study revealed how the fingerprint examination community shared their knowledge and collectively created criteria and rules toward coherent practices and decision making. Although the participants were knowledgeable practitioners, they needed to articulate new rules and operational practices for learning to work productively with the new tools. Within the present kind of visualization-rich professional domain, it is very hard to come up with unambiguous norms of professional conduct. Accordingly, there are "grey areas" where only professional's experience and competence determine the final decision of the unknown latent with value-laden common knowledge (Edwards, 2011). The developmental seminars we organized aimed at building a new kind of epistemic professional culture (Nerland \& Jensen 2012) anchored in deliberately cultivated examination methods and practices integrating professional with scientific knowing. Toward that end, the examiners were pushed to make their investigative practices visible and jointly reflect on and transform them. It appeared necessary to make the examination practices more transparent and evidence-based in nature. Moving toward more collective examination practices requires sharing of expertise that, in turn, is not possible without working out a metalanguage for talking about various intangible aspects of examination. 
Although it is evident that established professional practices transform slowly, the seminars provided a fertile ground for further developmental efforts. The proactive actions of the Forensic Laboratory were timely and correspond to suggestions of Dror and other (2011) as well as the National Academy of Science (NAS) report, and a number of scientific studies. Yet, common agreement about the criteria of fingerprint examination has not been reached. Development of the organizations with varying practices and processes takes time. Simultaneously, it is, however, necessary to find consistent, reliable, and transparent way of producing forensic reports for citizens and the authorities. At the time of collecting the data, the present Forensic Laboratory had 4-5 examination guidelines; at the time of writing this article, there are altogether 20 codes of conduct, concerning, for instance, comparative examination of fingerprints, a practical guide for AFIS and LIMS, documentation of fingerprint examination with GYRO color coding and other practical guides for the examiners. To solve the dilemma of forensic decision making, the increasing number of forensic fingerprint scientific studies has brought a variety of different kind of solution models, e.g., likelihood ratio, probability, Bayesian approach, and Linear Sequential Unmasking approach LSU (Dror et al. 2015). Currently, these models are not, however, used in Finland.

The present investigation illustrated how the traditional examination practices based on personal professional competencies developed through apprenticeship and long experience were giving away to more reflective and collective competencies based not only on national but also international standards. Simultaneously, it is important to remember that the quality of fingerprint examination also requires sophisticated and personally cultivated professional competencies (Dror et. al., 2011). In order to develop fingerprint examination toward that direction, it is necessary to transform prevailing training methods. Thus far, forensic institutes have not found common agreement and standards for fingerprint examiners' training requirements. Most of the training is carried out inside organisations without or with only few quality assessment tools. In addition to this, there are some international fingerprint identification tests (e.g., CTS, ENFSI) for fingerprint examiners. In Finland, elements of certification have been built up inside the training programme (see Mustonen \& Hakkarainen, 2015; Mustonen \& Himberg, 2011). Studies of Mustonen and her colleagues indicate that it is critical to engage apprentices in systematic cultivation of their adaptive expertise in integrating professional and scientific knowing, following transparent examination practices, and deliberate reflection on professional practices so as to sort out conflicting decisions (Mustonen et al. 2015). It appears productive to engage current trainees in efforts to develop more transparent and rigorous norms and criteria of examination, in interaction with experienced ones. Two trainees were, indeed, participating in the present developmental seminars and continued their training with associated research reports (Mustonen \& Hakkarainen, 2015).

The seminars allowed the fingerprint community to explore digitally enhanced practices of problem solving, communication, and process flow management. Distributing of investigations across several independent examiners appeared to enhance transparency and accountability of the analysis process and decisions. Although communication between different new systems and optimization of shared operational procedure remained a challenge, these problems are likely to be solved due to the rapid development of digital instruments. Simultaneously, the digital technologies enable construction of technology-supported collaborative learning spaces (e.g., e-learning), coconstructing and constantly updating examination guidelines (e.g., Wiki model) or sharing large bodies of scientific knowledge with the professional community (e-science); such resources provide positive future trajectories for the development of the forensic industry. These instruments and methods are also likely to assist in improving the quality of the forensic investigation industry, enlarge associated bodies of professional knowledge and make knowledge processes more 
analysable. They will establish more open possibilities of meaningful negotiations and constructive, critical thinking within professional communities and formal organizations. 


\section{References}

Ashbaugh, D. (1999). Quantitative-Qualitative Friction Ridge Analysis: An Introduction to Basic and Advanced Ridgeology. New York: CRC Press LCC.

Black, J. P. (2012). Is There a Need for 100\% Verification (Review) of Latent Print Examination Conclusions? Journal of Forensic Identification, 62 (1), 80-100.

Charlton, D., Frazer-Mackenzie, P. A. F., \& Dror, I. E. (2010). Emotional Experiences and Motivation Factors Associated with Fingerprint Analysis. Journal of Forensic Sciences, 55 (2), 385-393. doi:10.111/j.1556-4029.2009.01295.x.

DiMaggio, P. J., \& Powell, W. W. (1983). The Iron Cage Revisited: Institutional Isomorphism and Collective Rationality in Organizational Fields. American Sociological Review, 48 (2), 147-60.

Dror, I.E. (2013). Practical Solutions to Cognitive and Human Factor Challenges in Forensic Science. Forensic Science Policy \& Management, 4(3-4), 1-9.

Dror, I. E. (2015). Context Management Toolbox: A Linear Sequential Unmasking (LSU) Approach for Minimizing Cognitive Bias in Forensic Decision Making. Journal of Forensic Sciences, 60 (4), 1111-1112. doi:10.1111/1556-4029.12805.

Dror, I. E. (2016). A Hierarchy of Expert Performance. Journal of Applied Research in Memory and Cognition, 5, 121-127.

Dror, I. E., Champod, C., Langenburg, G., Charlton, D., Hunt, H., \& Rosenthal, R. (2011). Cognitive Issues in Fingerprint Analysis: Inter- and Intra-expert Consistency and the Effect of a 'Target' Comparison. Forensic Science International, 208, 10-17.

Dror, I. E., \& Charlton, D. (2006). Why Expert Make Errors. Journal of Forensic Identification, 56 (4), 600-616.

Dror, I. E., \& Hampikian, G. (2011). Subjectivity and Bias in Forensic DNA Mixture Interpretation. Science and Justice 51, 204-208.

Dror, I. E., Péron, A., Hind, S.-L., \& Charlton, D. (2005). When Emotions Get The Better of Us: The Effect on Contextual Top-down Processing On Matching Fingerprints. Applied Cognitive Psychology. 19 (6), 799-809.

Dror, I. E., \& Rosenthal, R. (2008). Meta-analytically Quantifying the Reliability and Biasability of Forensic Experts. Journal of Forensic Sciences, 53(4), 900-903. doi:10.1111/j.15564029.2008.00762.x

Dror, I. E., Thompson, W. C., Meissner, C. A., Kornfield, I. Krane, D., Saks, M., \& Risinger, M. (2015). Context Management Toolbox: A Linear Sequential Unmasking (LSU) Approach for Minimizing Cognitive Bias in Forensic Decision Making. Journal of Forensic Sciences, 60 (4). doi:10.1111/1556-4029.12805.

Edwards, A. (1995). Relational Agency: Learning To be A Resourceful Practitioner. International Journal of Educational Research, 43, 168-182. doi:10.1016/j.ijer.2006.06.010.

Edwards, A. (2011). Building Common Knowledge at the Boundaries between Professional Practices: Relational Agency and Relational Expertise in Systems of Distributed Expertise. International Journal of Educational Research, 50, 33-39. doi:10.1016/j.ijer.2011.04.007.

Edwards, A. (2012). The Role of Common Knowledge in Achieving Collaboration across Practices. Learning, Culture, and Social Interaction, 1, 22-32. 
Edwards, A., \& Daniels, H. (2012). The Knowledge that Matters in Professional Practices. Journal of Education and Work, 25(1), 39-58. doi:10.1080/13639080.2012.644904.

Engeström, Y. (1987). Learning by Expanding: An Activity-Theoretical Approach to Developmental Research, Orienta-Konsultit, Helsinki.

Engeström, Y. (2001). Expansive Learning at Work: Toward an Activity Theoretical Reconceptualization. Journal of Education and Work. 14:1, 133-156. Retrieved: http://dx.doi.org/10.1080/13639080020028747

Ericsson, K. A. (2006). The Influence of Experience and Deliberate Practice on the Development of Superior Expert Performance. In K. A. Ericsson, N. Chariness, P. Feltovich, \& R. Hoffman (Eds.) The Cambridge Handbook of Expertise and Expert Performance, 683-704. Cambridge, MA: Cambridge University Press.

Goodwin, C. (1994). Professional Vision. American Anthropologist, 96 (3), 606-633.

Heritage, J. (1984). Garfinkel and Ethnomethodology. Cambridge: Polity Press.

Houses of Parliament. (2015a). Unintentional Bias in Forensic Investigation. The Parliamentary Office of Science and Technology, POSTbrief 15. Retrieved: www.parliament.uk/post

Houses of Parliament. (2015b). Unintentional Bias in Court. The Parliamentary Office of Science and Technology, POSTNOTE 512. Retrieved: www.parliament.uk/post

Jensen, K., Lahn, L. C., \& Nerland, M. (2012). Introduction. In K. Jensen, L. C. Lahn, M. Nerland (Eds.). Professional learning in the knowledge society, 1-24. Rotterdam, The Netherlands: Sense.

Kassin, S. M., Dror, I. E., \& Kukucka, J. (2013). The Forensic Confirmation Bias: Problems, Perspectives, and Proposed Solutions. Journal of Applied Research in Memory and Cognition, 2, 42-52.

Krippendorf, K. (2013). Content Analysis: An Introduction to Its Methodology. Los Angeles, CA: SAGE.

Kruger, J. M., \& Dunning, D. (1999). Unskilled and Unaware of It: How Difficulties in Recognizing One's Own Incompetence Lead to Inflated Self-assessments. Journal of Personality and Social Psychology, 77 (6), 1121-1134.

Langenburg, G., \& Champod, C. (2011). GYRO System - A Recommended Approach to More Transparent Documentation. Journal of Forensic Identification 61 (4), 373-384.

Leiter, K. (1980). A Primer on Ethnomethodology. Oxford: Oxford University Press.

Maceo, A. V. (2009). Qualitative Assessment of Skin Deformation: A Pilot Study. Journal of Forensic Identification, 59(4):390-440.

Mattijssen, E. J. A. T., Kerkhoff, W., Berger C. E. H., Dror, I. E., \& Stoel, R. D. (2016). Implementing Context Information Management in Forensic Casework: Minimizing Contextual Bias in Firearms Examination. Science and Justice, 56 (2), 113-122.

doi:10.1016/j.scijus.2015.11.004.

Mustonen, V., \& Hakkarainen, K. (2015). Tracing Two Apprentices' Trajectories Toward Adaptive Professional Expertise in Fingerprint Examination. Vocations and Learning, 8:185-211. doi:10.1007/s12186-015-9130-7.

Mustonen, V., Hakkarainen, K., Tuunainen, J., \& Pohjola, P. (2015). Discrepancies in Expert Decision-making in Forensic Fingerprint Examination. Forensic Science International, 254, 215 226. 
Mustonen, V., \& Himberg, K. (2011). A Novel Approach to the Education of Fingerprint Experts. Forensic Science Policy and Management: An International Journal, 2 (1), 28-35.

National Academy of Sciences (NAS). (2009). Strengthening Forensic Science in the United States. A Path Forward. https://www.ncjrs.gov/pdffiles1/nij/grants/228091.pdf.

Nerland, M. (2012). Professions as Knowledge Cultures. In K. Jensen, L. C. Lahn, M. Nerland (Eds.). Professional learning in the knowledge society, 27-48. Rotterdam, The Netherlands: Sense.

Nerland, M., \& Jensen, K. (2012). Epistemic Practices and Object Relations in Professional Work. Journal of Education and Work, 25, 101-120.

Polanyi, M. (1966). The Tacit Dimension. Gloucester, MA, Peter Smith, reprinted 1983.

Saks, M. J., \& Koehler, J. J. (2005). The Coming Paradigm Shift in Forensic Identification Science. Science New Series, 309(5736), 892-895.

Saldaña, J. (2012). The Coding Manual for Qualitative Researcher. Los Angeles, CA: SAGE.

Schank, R. C. (1999). Dynamic Memory Revisited. USA: Cambridge University Press.

Schatzki, T. R. (1996). Social Practices: A wittgensteinian approach to human activity and the social. Cambridge: Cambridge University Press.

Schatzki, T. R. (2002). The Site of the Social. Pennsylvania University Press.

Schiffer, B., \& Champod, C. (2007). The Potential (negative) Influence of Observational Biases at the Analysis Stage of Fingermark Individualisation. Forensic Science International 167, 116-120.

The Scientific Working Group on Friction Ridge Analysis, Study and Technology SWGFAST. (2014, 13 May). Standard for the documentation of analysis, comparison, evaluation, and verification (ACE-V), (LATENT). Resource document. http://www.swgfast.org/Documents.html.

The Scientific Working Group on Friction Ridge Analysis, Study and Technology SWGFAST. (2014, 13 May). Standards for examining friction ridge impressions and resulting conclusion. Resource document. http://www.swgfast.org/Documents.html.

Ulery, B. T., Hicklin, R. A., Roberts, M. A., \& Buscaglia, J. (2016). Data on the interexaminer variation of minutia markup on latent fingerprints. Data in Brief 8, 158-190.

Ulery, B. T., Hicklin, R. A., Roberts, M. A., \& Buscaglia, J. (2014). Changes in latent fingerprint examiners' markup between analysis and comparison. Forensic Science International 247, 54-61.

Ulery, B. T., Hicklin, R. A., Buscaglia, J., \& Roberts, M. A. (2011), Accuracy and reliability of forensic latent fingerprint decisions, Proc. Natl. Acad. Sci. USA, 108, 7733-7738.

U.S. Department of Justice. Office of the Inspector General (2006). A Review of the FBI's Handling of the Brandon Mayfield Case. Oversight and Review Division.

https://oig.justice.gov/special/s0601/final.pdf.

Vygotsky, L. S. (1978). Mind in Society. The Development of Higher Psychological Processes. USA: Harvard University Press.

Winch, P. (1958). The Idea of Social Science and its Relation to Philosophy. London: Routledge.

Wittgenstein, L. (2001) [1953]. Philosophical Investigations. Oxford: Blackwell Publishing. 